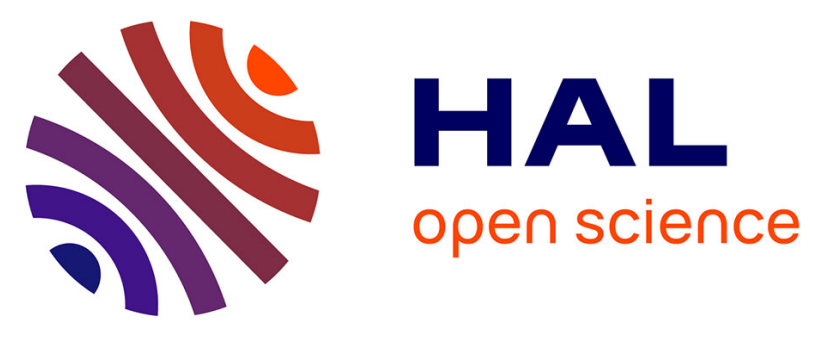

\title{
The stability number as a metric for electrocatalyst stability benchmarking
}

Simon Geiger, Olga Kasian, Marc Ledendecker, Enrico Pizzutilo, Andrea M

Mingers, Wen Tian Fu, Oscar Diaz-Morales, Zhizhong Li, Tobias Oellers, Luc

Fruchter, et al.

\section{To cite this version:}

Simon Geiger, Olga Kasian, Marc Ledendecker, Enrico Pizzutilo, Andrea M Mingers, et al.. The stability number as a metric for electrocatalyst stability benchmarking. Nature Catalysis, 2018, 10.1038/s41929-018-0085-6 . hal-02390894

\section{HAL Id: hal-02390894 \\ https://hal.science/hal-02390894}

Submitted on 3 Dec 2019

HAL is a multi-disciplinary open access archive for the deposit and dissemination of scientific research documents, whether they are published or not. The documents may come from teaching and research institutions in France or abroad, or from public or private research centers.
L'archive ouverte pluridisciplinaire HAL, est destinée au dépôt et à la diffusion de documents scientifiques de niveau recherche, publiés ou non, émanant des établissements d'enseignement et de recherche français ou étrangers, des laboratoires publics ou privés. 


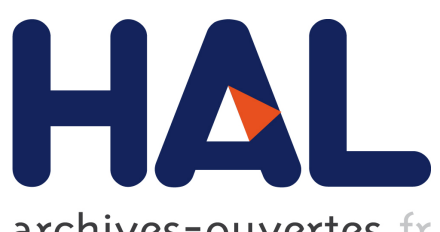

archives-ouvertes

\section{The stability number as a metric for electrocatalyst stability benchmarking}

Simon Geiger, Olga Kasian, Marc Ledendecker, Enrico Pizzutilo, Andrea

Mingers, Wen Fu, Oscar Diaz-Morales, Zhizhong Li, Tobias Oellers, Luc

Fruchter, et al.

\section{To cite this version:}

Simon Geiger, Olga Kasian, Marc Ledendecker, Enrico Pizzutilo, Andrea Mingers, et al.. The stability number as a metric for electrocatalyst stability benchmarking. Nature Catalysis, Nature Publishing Group, 2018. hal-02390894

\section{HAL Id: hal-02390894 \\ https://hal.archives-ouvertes.fr/hal-02390894}

Submitted on 3 Dec 2019

HAL is a multi-disciplinary open access archive for the deposit and dissemination of scientific research documents, whether they are published or not. The documents may come from teaching and research institutions in France or abroad, or from public or private research centers.
L'archive ouverte pluridisciplinaire $\mathbf{H A L}$, est destinée au dépôt et à la diffusion de documents scientifiques de niveau recherche, publiés ou non, émanant des établissements d'enseignement et de recherche français ou étrangers, des laboratoires publics ou privés. 
4 Simon Geiger ${ }^{\mathrm{a}, \uparrow, *}$, Olga Kasian ${ }^{\mathrm{a}, \dagger}$, Marc Ledendecker ${ }^{\mathrm{a}}$, Enrico Pizzutilo ${ }^{\mathrm{a}}$, Andrea M. Mingers ${ }^{\mathrm{a}}$, Wen Tian Fu ${ }^{\mathrm{b}}$, Oscar Diaz-Morales ${ }^{\mathrm{b}}$, Zhizhong $\mathrm{Li}^{\mathrm{c}}$, Tobias Oellers ${ }^{\mathrm{d}}$, Luc Fruchter ${ }^{\mathrm{c}}$, Alfred Ludwig $^{\mathrm{d}}$, Karl J. J. Mayrhofer ${ }^{\mathrm{a}, \mathrm{e}, \mathrm{f}}$, Marc T. M. Koper ${ }^{\mathrm{b}}$, Serhiy Cherevko, ${ }^{\mathrm{a}, \mathrm{e}, *}$

a Department of Interface Chemistry and Surface Engineering, Max-Planck-Institut für Eisenforschung GmbH, 40237 Düsseldorf, Germany ${ }^{\mathrm{b}}$ Leiden Institute of Chemistry, Leiden University, Leiden 2300 RA, The Netherlands.

${ }^{\mathrm{c}}$ Laboratoire de Physique des Solides, C.N.R.S., Université Paris-Sud, 91405 Orsay, France ${ }^{\mathrm{d}}$ Institute for Materials, Ruhr-Universität Bochum, 44801 Bochum, Germany ${ }^{\mathrm{e}}$ Helmholtz-Institute Erlangen-Nürnberg for Renewable Energy (IEK-11), Forschungszentrum Jülich, 91058 Erlangen, Germany

${ }^{\mathrm{f}}$ Department of Chemical and Biological Engineering, Friedrich-Alexander-Universität Erlangen-Nürnberg, 91058 Erlangen, Germany 17 
31 Reducing noble metal loading and increasing specific activity of oxygen evolution catalysts 32 are omnipresent challenges in proton exchange membrane (PEM) water electrolysis, which have recently been tackled by utilizing mixed oxides of noble and non-noble elements (e.g. perovskites, $\mathrm{IrNiO}_{\mathrm{x}}$, etc.). However, proper verification of the stability of these materials is still pending. In this work dissolution processes of various iridium-based oxides are explored by introducing a new metric, defined as the ratio between amount of evolved oxygen and dissolved iridium. The so called Stability-number is independent of loading, surface area or involved active sites and thus, provides a reasonable comparison of diverse materials with respect to stability. Furthermore it can support the clarification of dissolution mechanisms and the estimation of a catalyst's lifetime. The case study on iridium-based perovskites shows that leaching of the non-noble elements in mixed oxides leads to formation of highly active amorphous iridium oxide, the instability of which is explained by participation of activated oxygen atoms, generating short-lived vacancies that favour dissolution. These insights are considered to guide further research which should be devoted to increasing utilization of pure crystalline iridium oxide, as it is the only known structure that guarantees a high durability in acidic conditions. In case amorphous iridium oxides are used, solutions for stabilization are needed.

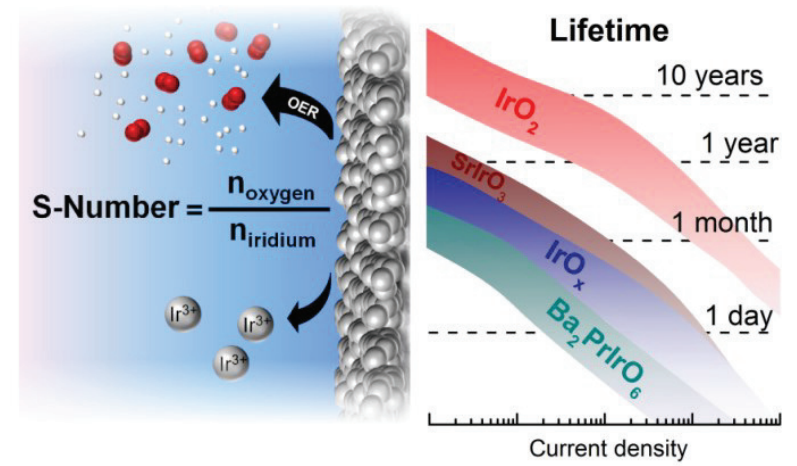

Keywords: oxygen evolution reaction, iridium, perovskites, stability-number, energy conversion 


\section{Introduction}

Electrochemical water splitting is considered to play a key role in the new energy scenario for the production of hydrogen, which can act as central energy carrier and as raw material for the chemical industry. Still, the persistent challenges of this concept are (i) slow kinetics of the oxygen evolution reaction (OER) and (ii) need of expensive materials as catalysts or related components. Especially for proton exchange membrane (PEM) electrolysis, the acidic environment caused by the membrane itself together with high anodic potentials limits the choice of catalyst materials to expensive noble metals. The best known catalysts for OER contain high amounts of scarce iridium that hampers large scale implementation of this technology. Smart catalyst design is needed to decrease noble metal loadings and increase specific activity and stability.

Various iridium-based mixed oxides ${ }^{1-8}$ have been investigated as potential catalyst material to tackle the mentioned challenges by increased specific activity and lower percentage of expensive noble metals. Enhanced activity and apparently decent stability was demonstrated in comparison to $\mathrm{IrO}_{2}$, Ir-black, or other benchmark materials. However, the stability aspect needs more rigorous investigation. Especially non noble alkali or rare earth elements are expected to be thermodynamically unstable in acidic electrolytes, ${ }^{9}$ favouring the formation of amorphous iridium oxide structures after leaching. The latter have been shown to degrade significantly in acidic electrolyte during OER, ${ }^{10-13}$ accentuating the need for further understanding of degradation processes.

Most prominent examples are iridium-based perovskites recently investigated in acidic electrolyte. $^{1,2}$ Initial studies on the usage of this material class in electrocatalysis originate from Bockris and Otagawa, ${ }^{14,15}$ who used alkaline electrolytes. Since then numerous studies on the usage of perovskites for alkaline water splitting have been published. ${ }^{16-25}$ Exceptionally high OER activities were achieved for example by varying the occupancy of $3 \mathrm{~d}$ orbitals of surface transition metals ${ }^{18}$ or tuning oxygen vacancies by means of straining. ${ }^{21}$ However, several groups brought up the important aspect of surface amorphization during OER. ${ }^{26-29}$ May et $a l .^{26}$ indicated, that especially those materials with high amorphization are the ones that show high activity, expressing the need of further investigations on the number of involved active sites. Even more in acid environment catalyst stability and amorphization is an issue. Therefore a thorough investigation of specific activity and dissolution processes of iridium-based perovskites in $0.1 \mathrm{M} \mathrm{HClO}_{4}$ is presented in this work. 
In general, contemporary challenges to explore new electrocatalysts are, in addition to increased activity: (i) the determination of the real electrochemical surface area (ECSA) by identification and quantification of the active sites enabling a reliable comparison of different materials and (ii) the investigation of degradation by thorough quantification of dissolution products, assuming the latter as major degradation process of electrocatalysts. Both parameters are important indicators of an electrocatalyst's performance. Our study aims to clear these important gaps by cyclic voltammetry to quantify active centres for OER and in situ dissolution data obtained by combining a scanning flow cell (SFC) with inductively coupled plasma mass spectrometry (ICP-MS). The amount of dissolved iridium is presented in relation to the evolved oxygen as new independent metric called Stability-number. The latter is beneficial to estimate lifetimes and together with online electrochemical mass spectrometry (OLEMS) underlines proposed dissolution mechanisms of the investigated materials, namely double perovskite powders with $\mathrm{A}_{2} \mathrm{BIrO}_{6}$ structure $(\mathrm{A}=\mathrm{Ba}, \mathrm{Sr} ; \mathrm{B}=\mathrm{Nd}, \mathrm{Pr}$, Y), amorphous $\mathrm{IrO}_{\mathrm{x}}$ powder, crystalline $\mathrm{IrO}_{2}$ powder, $\mathrm{SrIrO}_{3}$ perovskite films, electrochemically formed hydrous $\mathrm{IrO}_{\mathrm{x}}$ films and crystalline $\mathrm{IrO}_{2}$ films. A general perspective on the applicability of the mentioned iridium oxide structures towards acidic water splitting is presented.

\section{Results and discussion}

\section{Leaching processes in perovskites}

The catalyst composition on the surface is essential for exploring electrochemical reactions at the catalyst-electrolyte interface. Therefore, the dissolution behaviour of all materials was investigated during initial contact with $0.1 \mathrm{M} \mathrm{HClO}_{4}$ at open circuit potential (OCP). While crystalline $\mathrm{IrO}_{2}$ and amorphous $\mathrm{IrO}_{\mathrm{x}}$ do not dissolve initially, perovskites do undergo intensive leaching. First of all the non-noble elements ( $\mathrm{Ba}, \mathrm{Sr}, \mathrm{Nd}, \mathrm{Pr}$, and $\mathrm{Y}$ ) dissolve as expected from available thermodynamic data ${ }^{9}$ for single elements and related experimental works $^{1,2}$ (see Tab. S1 and Fig. S1, S3). However, in double-perovskites we observed dissolution of iridium as well in the range of $30-40 \mathrm{w} \%$ from the initial value, during $60 \mathrm{~s}$ of contact at OCP. This can be explained on the basis of the crystal structure

116 illustrated in Fig. 1b. As the component B (e.g. Pr) is part of the lattice, leaching of the latter 117 goes hand in hand with generation of isolated $\mathrm{IrO}_{6}$ octahedra, which are prone to dissolve in 118 parallel. Furthermore we expect that the structure will collapse and reform in an amorphous iridium oxide. To underline this statement one exemplary material of the double perovskite 
120 family was examined during a prolonged leaching experiment. EDS analysis confirms 121 complete removal of $\mathrm{Ba}$ and $\mathrm{Pr}$ after keeping the powder for 14 days in $0.1 \mathrm{M} \mathrm{HClO}_{4}$, leaving 122 behind an amorphous iridium oxide structure, demonstrated by selected area electron diffraction (SAED) (see Fig. S2). The penetration depths of these methods are expected to be

124 higher than the diameter of the investigated particle, hence, leaching and formation of 125 amorphous iridium oxide is not restricted to the surface.

126 Single perovskites on the other hand consist of a coherent iridium oxide structure with 127 intercalated non-noble elements (see Fig. 1c). Thus, initial dissolution of a $20 \mathrm{~nm} \mathrm{SrIrO}_{3}$ film 128 is restricted to $\mathrm{Sr}(3.0 \mathrm{w} \%)$, while iridium oxide is fairly stable $(0.01 \mathrm{w} \%)$ (see Fig. S3). The 129 leftover backbone of iridium oxide equals an anatase structure. ${ }^{1,30}$ However, no stable anatase 130 phase of iridium oxide has been reported to the best of our knowledge. It is therefore highly 131 probable that the structure will collapse as well into amorphous iridium oxide. Similar CV 132 shapes of electrochemically grown hydrous $\mathrm{IrO}_{x}$ and leached $\mathrm{SrIrO}_{3}$ presented in Fig. 4d 133 supports this assumption. Based on the obtained dissolution data and simple calculation, 134 initial contact of $\mathrm{SrIrO}_{3}$ with acid forms a $0.6 \mathrm{~nm}$ layer of hydrous iridium oxide, which 135 increases in thickness during prolonged OER measurements (see Fig. S3).
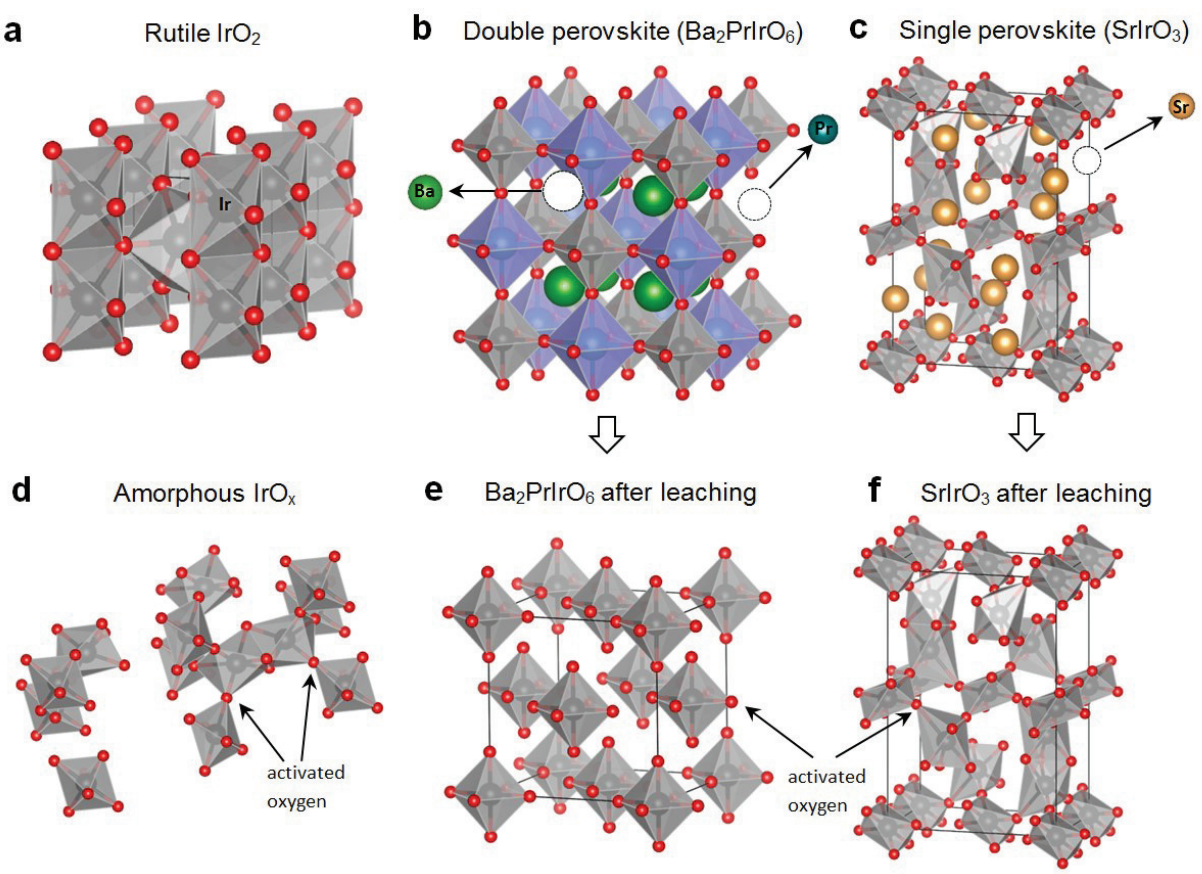

Figure 1. Crystal structure of the investigated materials. (a) rutile $\mathrm{IrO}_{2}$; (b) double perovskite (e.g. $\left.\mathrm{Ba}_{2} \mathrm{PrIrO}_{6}\right)$; (c) single perovskite $\left(\mathrm{SrIrO}_{3}\right)$; (d) assumed structure of amorphous iridium oxide, gaps are filled with intercalated water molecules (not shown); (e) leached double perovskite showing isolated $\mathrm{IrO}_{6}$ octahedra, which will collapse into an amorphous structure; (f) leached $\mathrm{SrIrO}_{3}$ resulting in an "anatase" iridium oxide structure. 


\section{The oxide structure and its relevance for activity and dissolution}

In order to understand the observed results on activity and stability presented later in the manuscript we continue with a discussion on oxide structures and oxidation states before and after the initial leaching process. In Fig. 1 the structures of rutile $\mathrm{IrO}_{2}$, amorphous $\operatorname{IrO}_{x}$, a double perovskite $\left(\mathrm{Ba}_{2} \mathrm{PrIrO}_{6}\right)$, and a single perovskite $\left(\mathrm{SrIrO}_{3}\right)$ are presented. The dense packing and edge sharing oxygen of the octahedra in the rutile structure are in contrast to loose packing and corner sharing octahedra in $\mathrm{Ba}_{2} \mathrm{PrIrO}_{6}$ and $\mathrm{SrIrO}_{3}$ generating lower coordinated oxygen atoms (activated oxygen). Leaching of the non-noble elements A and B in $\mathrm{A}_{2} \mathrm{BIrO}_{6}$ destroys the crystal structure of the double perovskite and pure octahedral elements are linked together randomly inducing a high number of accessible "activated oxygen atoms" and vacancies. Similar structures can be achieved by leaching $\mathrm{Sr}$ from $\mathrm{SrIrO}_{3}$ or Ni from $\mathrm{IrNiO}_{\mathrm{x}}{ }^{3,4}$ Moreover, classical potential cycling of iridium metal ${ }^{31}$ or mild calcination of iridium precursors ${ }^{11,32}$ are optional preparation methods.

The binding energies of the $4 \mathrm{f}$ electrons of iridium and $1 \mathrm{~s}$ electrons of oxygen obtained via X-ray photoemission spectroscopy (XPS) are utilized for further analysis on the chemical environment of iridium and oxygen in the structure. Based on a computational model, Pfeifer et al. ${ }^{33}$ studied the formation of an iridium vacancy in a supercell. According to the calculations, this leads to the formation of $\mathrm{O}^{\mathrm{I}-}$ and $\mathrm{Ir}^{\mathrm{III}}$ species, which was supported by XPS and NEXAFS investigations. Hereby, the authors explained the positive shift of the Ir 4f binding energy ${ }^{33}$ in amorphous $\operatorname{IrO}_{x}$, which is shown in Fig. 2a. The $\operatorname{Ir} 4 \mathrm{f}$ peak of $\mathrm{Ba}_{2} \mathrm{PrIrO}_{6}$ is shifted to even higher binding energies, however, the pristine structure rather indicates the presence of $\mathrm{Ir}^{\mathrm{V}}$, which has a similar peak shift. ${ }^{34}$ Still, Fu et al. ${ }^{35}$ found a $\operatorname{Pr}^{\mathrm{IV}} / \mathrm{Ir}^{\mathrm{IV}}$ couple present in $\mathrm{Ba}_{2} \mathrm{PrIrO}_{6}$, which is against the previous assumption. Consequently, based on XPS data solely, a clear statement on the oxidation states cannot be made. However, XPS clearly expresses the different environment of the iridium atoms in the respective structures. After leaching of $\mathrm{Ba}_{2} \mathrm{PrIrO}_{6}$ in $0.1 \mathrm{M} \mathrm{HClO}_{4}$ the spectrum is very similar to amorphous iridium oxide (see Fig. S2c, d). This observation could be understood as a decreased amount of $\mathrm{Ir}^{\mathrm{VI} / \mathrm{V}}$ and the formation or Ir $^{\mathrm{III}}$ by intensive leaching and creation of vacancies similar to the theoretical model mentioned earlier in this section.

The $\mathrm{O}$ 1s spectra in Fig. $2 \mathrm{~b}$ confirm that exclusively crystalline $\mathrm{IrO}_{2}$ contains oxygen atoms in the rutile lattice at a binding energy of $\sim 530 \mathrm{eV}$. In perovskites and amorphous oxide, the binding energy of the main peak is shifted to positive values, which is usually assigned to hydroxyl groups. ${ }^{4}$ Alternatively, it could be attributed to oxygen atoms 
176 with different environment, e.g. activated oxygen atoms. The shoulder at $529 \mathrm{eV}$ for $177 \mathrm{Ba}_{2} \mathrm{PrIrO}_{6}$ results from lattice oxygen bound to the $\mathrm{Pr}$ atom ${ }^{2}$ and disappears after extensive 178 leaching (see Fig. S2). Similar absorption features were observed by Reier et al. ${ }^{4}$ in the case of $\mathrm{IrNiO}_{\mathrm{x}}$ and explained by "oxygen hole" states induced by substitution of $\mathrm{Ir}^{4+}$ with $\mathrm{Ni}^{2+}$.

We suggest that the presence of activated oxygen atoms is crucial for the explanation of the following results in activity and dissolution. The dense packing of the rutile

182 structure restricts the formation of activated oxygen atoms to the surface, which is 183 undercoordinated by definition. In contrast, for porous hydrous oxides with intercalated water 184 molecules ${ }^{37,38}$ iridium atoms inside the structure can participate in the reaction. These centres are surrounded by a higher number of activated oxygen atoms and weaker in coordination facilitating their instability (see discussion on mechanism and Stability-number).
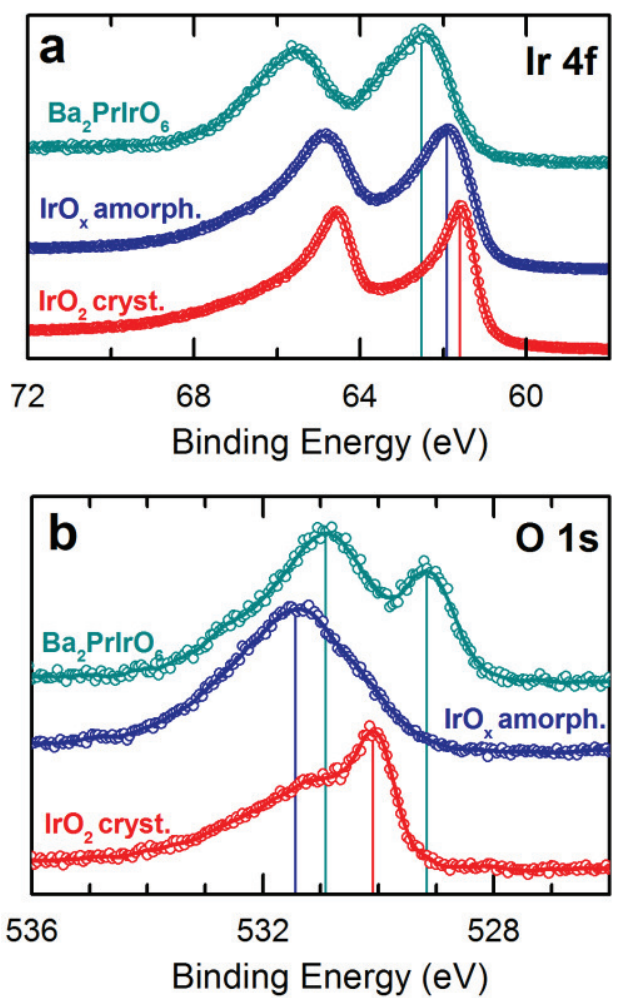
spectra. Additional results of the leached $\mathrm{Ba}_{2} \mathrm{PrIrO}_{6}$ are presented in the supporting information (Fig. S2). 
The SFC coupled to ICP-MS analytics enables in situ detection of dissolved iridium ions during the oxygen evolution. This approach was used to investigate film and powder materials by performing a linear sweep of potential at $5 \mathrm{mV} \mathrm{s}^{-1}$, illustrated in Fig. $3 \mathrm{a}$ and $3 \mathrm{~b}$. Potential and dissolution are plotted on the same time scale. The insets present the integrated amount on a logarithmic scale. In line with previous reports we recorded orders of magnitude higher dissolution for metallic iridium and hydrous iridium oxide in comparison to crystalline iridium oxide. $^{10,39}$ Perovskites, additionally studied in this work, show as well high dissolution in the range of amorphous/hydrous oxide and therefore might not be suitable for long time operation. Still, the high activity of the latter, demonstrated in the following, is of importance to understand the clues on the synthesis of an improved OER catalyst.

Powders:

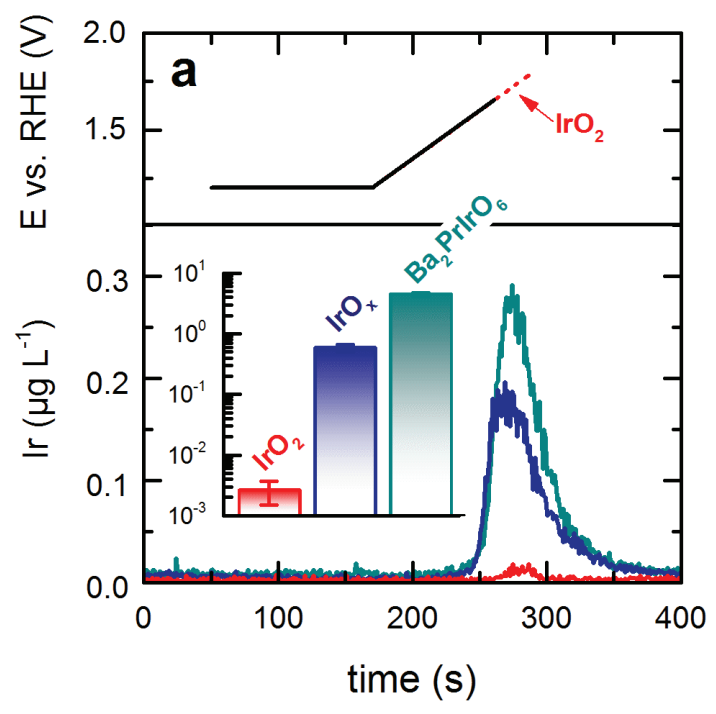

Films:

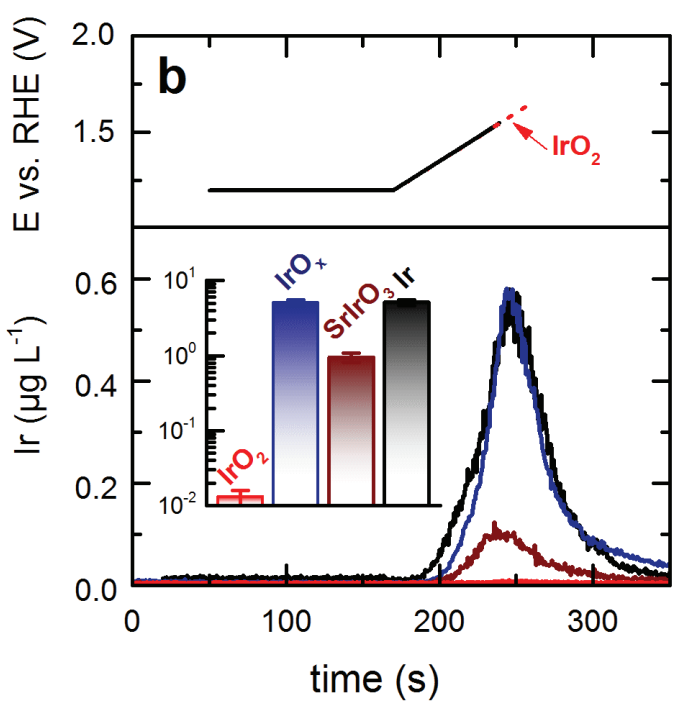
.

Figure 3. Investigation of iridium dissolution during OER. (a) Detected iridium concentration in the electrolyte during the $2^{\text {nd }}$ linear scan of potential to $1.65 \mathrm{~V}$ vs. RHE for investigated powders. In case of $\mathrm{IrO}_{2}$ a higher loading was used and the potential was increased to $1.8 \mathrm{~V}$ vs. RHE in order to reach iridium concentrations above the detection limit of the ICP-MS. Inset: integrated dissolution normalized by the actual mass of iridium loaded given in $n g \mathrm{~g}_{\mathrm{Ir}}{ }^{-1}$. (b) Detected iridium concentration in the electrolyte during a linear scan of potential to $1.55 \mathrm{~V}$ vs. RHE for investigated films. In case of $\mathrm{IrO}_{2}$ the potential was increased to $1.65 \mathrm{~V}$ vs. RHE. Inset: integrated dissolution normalized to the geometric surface area given in $\mathrm{ng} \mathrm{cm}{ }^{-2}$.

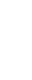

政 
In order to take into account the different active surface areas of the samples the

221 OER-current is normalized to the pseudocapacitive charge Qoxide extracted from the cyclic voltammograms in the range of 0.4 to $1.3 \mathrm{~V}$ vs. RHE (Fig. 4). Qoxide is considered as a fair approximation $^{40-43}$ for the number of involved active sites, avoiding misinterpretation of data on activity due to surface area effects. Based on the position of the redox peak in Fig. 4b we assume that predominantly $\operatorname{Ir}^{\mathrm{IV}} / \mathrm{Ir}^{\mathrm{V}}$ transition ${ }^{37,44}$ appears in perovskites while $\mathrm{Ir}^{\mathrm{III}} / \mathrm{Ir}^{\mathrm{IV}}$ is suppressed. In commercial amorphous $\mathrm{IrO}_{\mathrm{x}}$ the $\mathrm{Ir}^{\mathrm{III}} / \mathrm{Ir}^{\mathrm{IV}}$ redox peak is much more pronounced with a second wave indicating further oxidation to $\operatorname{Ir}^{\mathrm{V}}$. Assuming that $\operatorname{Ir}^{\mathrm{V}}$ is essential for fast OER kinetics, high presence of this species in perovskites could explain their superior activity in comparison to $\mathrm{IrO}_{\mathrm{x}}$ and $\mathrm{IrO}_{2}$. Alternatively the numerous activated oxygen atoms present in $\mathrm{Ba}_{2} \mathrm{PrIrO}_{6}$ due to complete isolation of $\mathrm{IrO}_{6}$ octahedral after leaching could be the reason for a boost in specific activity. Normalization of OER activity to the actual mass of iridium is shown in Fig. S5. Even though perovskite particles tested in this work are large in size (Fig. S4), high activities were achieved, which is another indication on the formation of a very active and highly porous layer.

In Fig. $4 \mathrm{c}$ and $4 \mathrm{~d}$ the analogous procedure is illustrated for sputtered samples. Low roughness of these films allows normalization to geometric surface area. Exceptions are leached $\mathrm{SrIrO}_{3}$ and electrochemically grown hydrous iridium oxide, investigated numerously in the literature. ${ }^{31,45,46}$ Both show enhanced pseudo capacitance assigned to the formation of a porous hydrous oxide layer. Almost identical CV shapes are indications on very similar structures of the latter. The extraordinary activity of these porous 3D-structures is, inter alia, related to the high number of accessible active sites. Normalization to pseudocapacitive charge, as mentioned for powder samples, is necessary to reveal further insights on the specific activity. The trend for specific activity is: $\mathrm{Ba}_{2} \mathrm{PrIrO}_{6}>\mathrm{SrIrO}_{3}=\mathrm{IrO}_{\mathrm{x}}>\mathrm{IrO}_{2}$, presented and discussed in the supporting information (Figs. S6 -S8). Focusing on the flat samples of iridium metal, crystalline $\mathrm{IrO}_{2}$ and pristine $\mathrm{SrIrO}_{3}$ with similar $\mathrm{Q}_{\text {oxide }}$ (Fig. 4d) one can conclude that the specific OER activity on $\mathrm{SrIrO}_{3}$ and metallic iridium is about two orders of magnitude higher in comparison to crystalline $\mathrm{IrO}_{2}$, caused by a thin hydrated oxide layer formed on $\mathrm{SrIrO}_{3}$ via leaching and metallic iridium via surface oxidation during OER, ${ }^{45}$ which is not present for crystalline iridium oxide. 

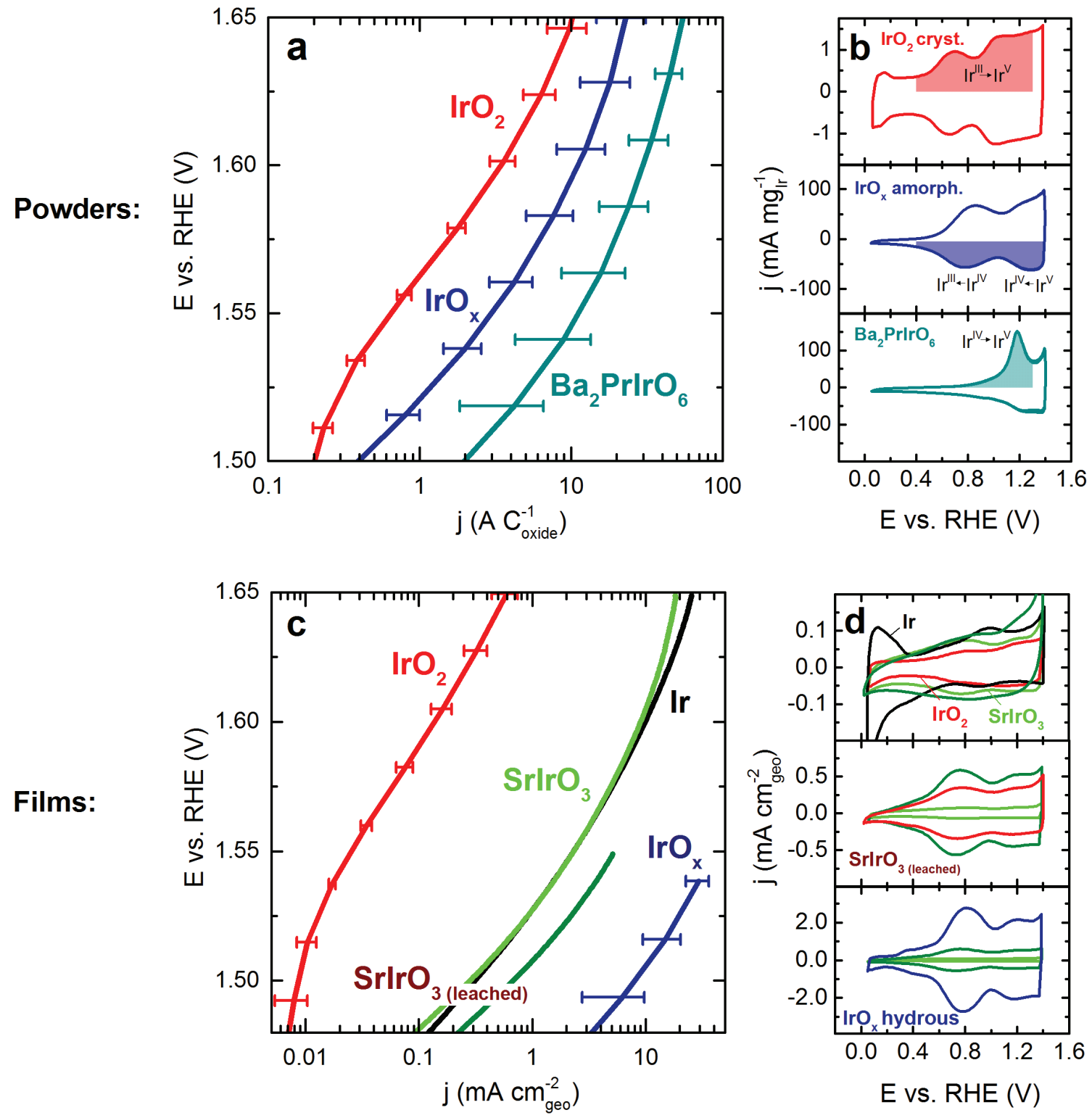

Figure 4. Comparison of the investigated materials in terms of activity. (a) OER-activity of the powder materials recorded with a linear scan of potential at $5 \mathrm{mV} \mathrm{s}^{-1}$ (iR-drop corrected). The current is normalized to the pseudocapacitive charge in the anodic scan between 0.4 and $1.3 \mathrm{~V}_{\mathrm{RHE}}$ at $200 \mathrm{mV} \mathrm{s}^{-1}$.

(b) Cyclic voltammograms recorded with $200 \mathrm{mV} \mathrm{s}^{-1}$, the integrated area of the oxide charge used for normalization is highlighted. (c) OER-activity of the investigated films recorded with a linear scan of potential at $5 \mathrm{mV} \mathrm{s}^{-1}$. The current is normalized to the geometric surface area. (d) Cyclic voltammograms recorded with $200 \mathrm{mV} \mathrm{s}^{-1}$. All measurements were carried out in $0.1 \mathrm{M} \mathrm{HClO}_{4}$ purged with argon. 
With the gained understanding on structure, dissolution, and activity, we want to combine existing mechanisms of the OER on iridium-based catalysts ${ }^{47-51}$ with a mechanism for simultaneous dissolution. Starting point is the differentiation of two oxygen species present either in crystalline iridium oxide or amorphous, hydrated iridium oxides and the significantly higher stability of the crystalline structure in comparison to the amorphous hydrated structure as presented in Fig. 3.

The case of amorphous hydrous oxide merits special attention, as its structure is still unknown. According to Pfeifer et al., ${ }^{51-53}$ enhanced activity of amorphous iridium oxide is caused by electrophilic $\mathrm{O}^{\mathrm{I}-}$ species that are preferred for nucleophilic attack by water, reducing the activation energy for the adsorption. Grimaud et al. ${ }^{29}$ came to similar conclusions using $\mathrm{La}_{2} \mathrm{LiIrO}_{6}$ as a model catalyst. There are several indications that the "activated oxygen atoms" as described in this work and the abovementioned " $\mathrm{O}^{-\mathrm{I}}$ species" are indeed interchangeable. The presence of $\mathrm{O}^{\mathrm{I}-}$ is, however, counterintuitive, as the high electronegativity of oxygen in comparison to iridium should hardly allow the allocation of a formal oxidation state of -1 . Based on structural investigation of different amorphous iridium oxides (e.g. hollandites), Willinger et al. ${ }^{54}$ concluded that the ratio between corner- and edgesharing $\mathrm{IrO}_{6}$ octahedra is determining the OER activity. Thus, a high number of corner sharing oxygen atoms (activated oxygen) facilitates the OER. Regardless of the formal oxidation state and termination, it was experimentally proven by ${ }^{18} \mathrm{O}$ labelling for Co-based perovskites, that activated oxygen can participate in the OER, which was taken as evidence for oxygen redox chemistry. ${ }^{50}$ Furthermore it is an important argument to explain the instability of amorphous iridium oxides. In the following, the term lattice oxygen accounts generally for all oxygen atoms that are part of the structure and is not exclusively limited to the described oxygen atoms of the rutile lattice. Evidence for the participation of oxygen from the lattice of iridium oxides is rare. One work of Fierro et al. ${ }^{55}$ contains indications on a participation, however, it focuses only on one type of oxide, the exact nature of which remains unclear and therefore does not allow further generalization and conclusions.

In order to resolve the extent of lattice oxygen participation during OER on rutile and amorphous iridium oxides (the final state for all unstable iridium-based oxides) in more detail a method of isotope labelling combined with online electrochemical mass spectrometry was used. The labelled $\operatorname{Ir}^{18} \mathrm{O}_{2}$ and $\operatorname{Ir}^{18} \mathrm{O}_{\mathrm{x}}$ films (for preparation see methods section) were polarized galvanostatically in $\mathrm{H}_{2}{ }^{16} \mathrm{O}$-based electrolyte and formation of volatile species with 
mass to charge ratios of $32\left({ }^{16} \mathrm{O}^{16} \mathrm{O}\right), 34\left({ }^{16} \mathrm{O}^{18} \mathrm{O}\right.$, and to a small extent $\left.{ }^{17} \mathrm{O}^{17} \mathrm{O}\right)$ and 36 $\left({ }^{18} \mathrm{O}^{18} \mathrm{O}\right)$ were measured online (see Fig. 5). In order to compensate the influence of naturally occurring $\mathrm{H}_{2}{ }^{18} \mathrm{O}$ isotopes in the $\mathrm{H}_{2}{ }^{16} \mathrm{O}$-based electrolyte, the same protocol was applied to unlabelled rutile $\mathrm{Ir}^{16} \mathrm{O}_{2}$ and hydrous $\mathrm{Ir}^{16} \mathrm{O}_{\mathrm{x}}$ prepared by identical procedures. During anodic polarization, both labelled and unlabelled rutile samples show similar formation of various oxygen products (Fig. 5a). This indicates that participation of lattice oxygen in the OER is absent or negligible. In contrast, the formation of $\mathrm{m} / \mathrm{z}=34$ and $\mathrm{m} / \mathrm{z}=36$ on $\operatorname{Ir}^{18} \mathrm{O}_{\mathrm{x}}$ is more intense in comparison to the unlabelled sample (Fig. 5b), denoting the instability of amorphous oxide lattice towards OER. However, the low measured intensities of $\mathrm{m} / \mathrm{z}=34$ and $\mathrm{m} / \mathrm{z}=36$ suggest that the major part of the evolved oxygen molecules is formed via water discharge. Gradual decrease of $\mathrm{m} / \mathrm{z}=34$ and $\mathrm{m} / \mathrm{z}=36$ signals on labelled $\operatorname{Ir}^{18} \mathrm{O}_{\mathrm{x}}$ indicates an exchange between lattice oxygen atoms and oxygen from water induced by the OER.

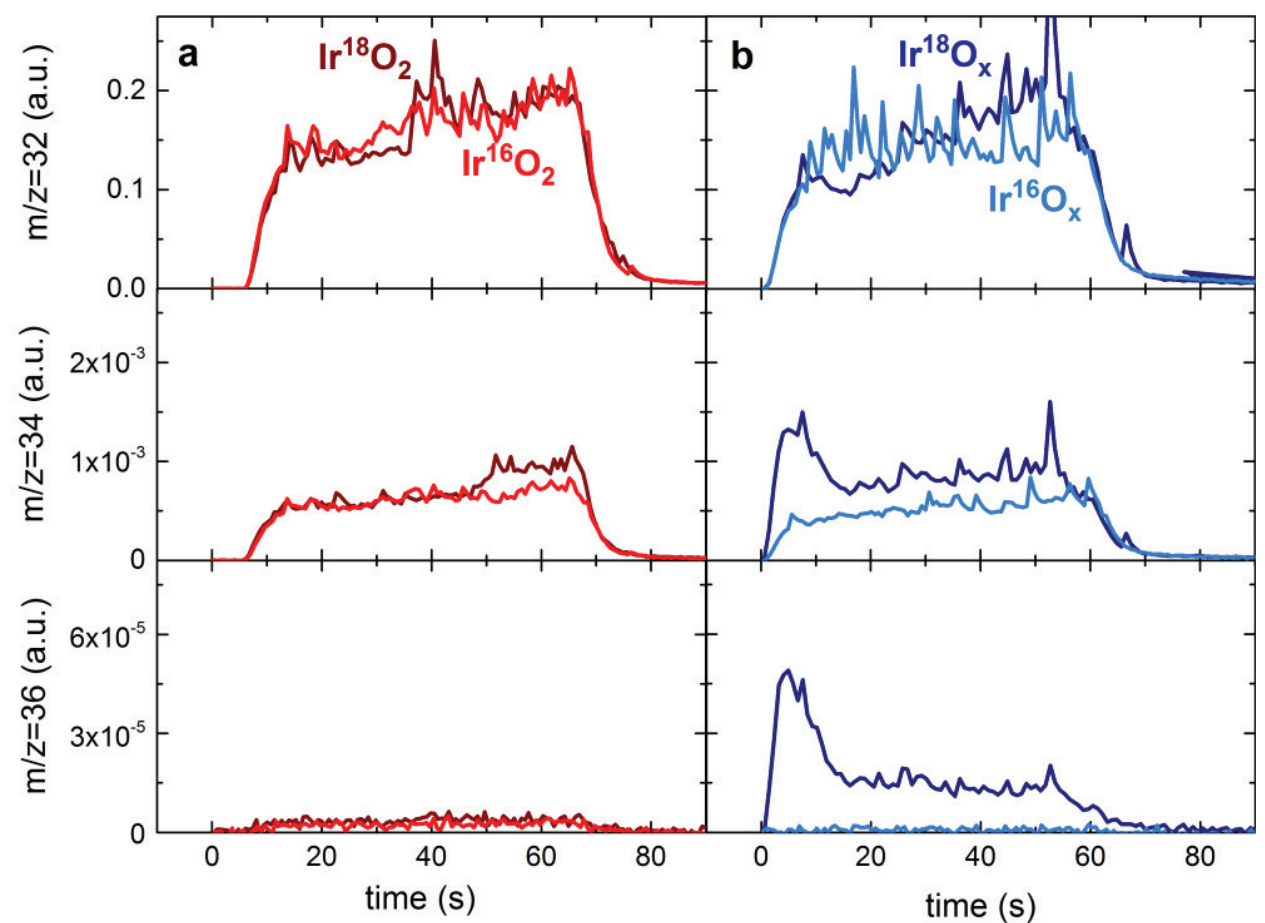

Figure 5. Online observation of lattice oxygen evolution on (a) rutile $\operatorname{Ir}^{18} \mathrm{O}_{2} / \operatorname{Ir}^{16} \mathrm{O}_{2}$ and (b) hydrous $\operatorname{Ir}{ }^{18} \mathrm{O}_{\mathrm{x}} /$ $\mathrm{Ir}^{16} \mathrm{O}_{\mathrm{x}}$ films during $60 \mathrm{~s}$ of anodic polarization at $25 \mathrm{~mA} \mathrm{~cm}{ }_{\text {geo. }}^{-2}$ The signals from $\mathrm{m} / \mathrm{z}$ of 32,34 and 36 correspond to ${ }^{32} \mathrm{O}_{2},{ }^{34} \mathrm{O}_{2}$ and ${ }^{36} \mathrm{O}_{2}$, respectively. Electrolyte: $0.1 \mathrm{M} \mathrm{HClO}_{4}$ in $\mathrm{H}_{2}{ }^{16} \mathrm{O}$.

Based on the results shown in Fig. 5 and additional data presented in literature, we propose a summarized view on the OER mechanisms in Fig. 6. On the left side, the classical mechanism on crystalline iridium oxide is presented as adsorbates evolution mechanism. ${ }^{47-49}$ The reaction can either happen on a single iridium site via an $\mathrm{OOH}$ intermediate ${ }^{34,56}$ (acid- 
base) ${ }^{48,57}$ or by the coupling of two oxygen atoms from different sites (direct coupling) ${ }^{58}$ For the cycle on the right side, we base ourselves on the mechanism proposed by Grimaud et al. ${ }^{50}$ and Rong et $a l .{ }^{49}$ Here, the reaction pathway differs by participation of activated (lattice) oxygen in the reaction. It is assumed to be operative in the case of amorphous $\mathrm{IrO}_{\mathrm{x}}$ and in leached perovskites. The activated oxygen is attacked by water (step 2) and removed as $\mathrm{O}_{2}$ from the surface (step 3) leaving behind an oxygen vacancy. ${ }^{49,50,59}$ This can either happen with one lattice oxygen or by combining two lattice oxygen atoms as shown in Fig. 5b, resulting in an iridium atom with two vacancies, which is highly probable to dissolve. The latter scenario is less likely to happen for crystalline oxide. Participation of lattice oxygen, if at all, is restricted to the outer surface while bulk oxygen will not participate and maintain a high coordination of the iridium atom, resulting in a significantly lower probability for the iridium atom to dissolve out of the structure. To close the cycle vacancies can be refilled by adsorption of water or bulk oxygen migration ${ }^{29}$ (step 1). We suggest the lower activation energy for the adsorption of water in vacancies is further contributing to the higher activity of amorphous oxide structures. Simultaneously, the weak bonding of iridium next to an oxygen vacancy is considered as the reason for dissolution of iridium in amorphous iridium oxide structures. In case more vacancies are created at the same time on one iridium atom, dissolution becomes even more preferable. Dissolution itself might take place without electron transfer $\operatorname{Ir}^{\mathrm{III}}{ }_{\text {(oxide) }} \rightarrow \operatorname{Ir}^{3+}{ }_{(\mathrm{aq})}$. A similar reaction pathway was proposed recently by our group, in which the existence of an $\mathrm{Ir}^{\mathrm{III}}$ intermediate in the OER cycle was linked to the dissolution of hydrous iridium oxide. ${ }^{60}$ Alternatively, additional electron transfer would lead to formation of $\mathrm{IrO}_{3}$ and $\mathrm{IrO}_{4}{ }^{2-}$, described elsewhere. ${ }^{61,62}$

As crystalline iridium oxide is assigned to the adsorbates evolution mechanism, its very low but still measurable dissolution is not considered, yet. The constancy of the Snumber presented in the following section (Fig. 7c), suggests a direct relation between the OER mechanism and the dissolution mechanism. The origin of the crystalline iridium oxide dissolution might be some limited lattice oxygen participation on the surface similar to the mechanism in Fig. 5b or other intermediates and dissolution pathways, e.g. formation of volatile $\mathrm{IrO}_{3}{ }^{61,62}$ (see further discussion in the $\mathrm{SI}$ ).

In conclusion, a catalyst's stability is determined by (i) the ratio between the two presented mechanisms (a less stable material has a higher rate in the lattice participated mechanism) and (ii) the stability of the intermediate itself, which can be higher for a rutile structure in comparison to the amorphous oxide due to a more compact structure. 
a

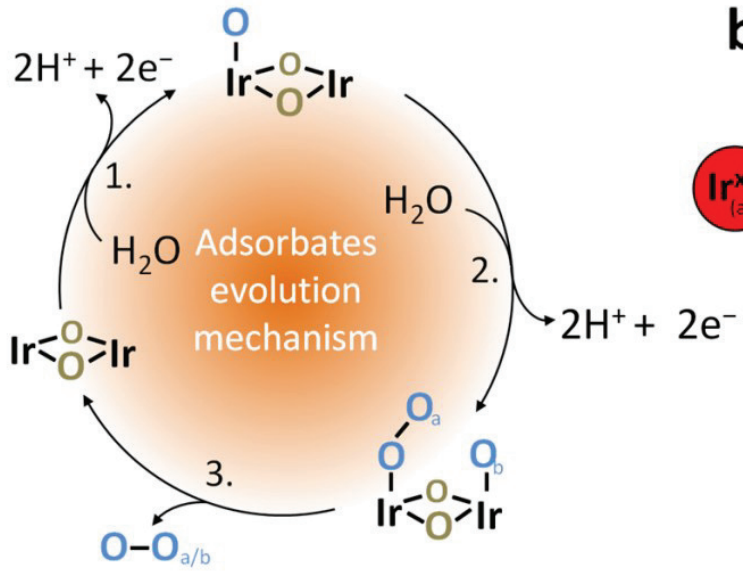

b

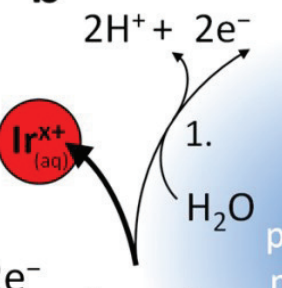

Ir- $\square-I r$

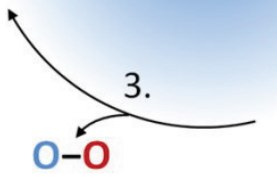

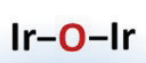

Lattice oarticipated mechanism

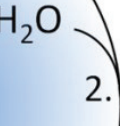

0 : lattice oxygen

0 : acitvated lattice oxygen

0 : adsorbed oxygen

$\square$ : oxygen vacancies

Figure 6. Sketch of the simplified OER reaction mechanism with dissolution pathway. (a) Classical mechanism for crystalline $\mathrm{IrO}_{2}$ without participation of lattice oxygen. Two possible pathways are presented: single site and double site. (b) Mechanism suggested for amorphous iridium oxide and leached perovskites with participation of activated oxygen in the reaction forming oxygen vacancies. Weakening the binding of iridium in the structure is taken as main reason for enhanced dissolution. To complete the cycle, vacancies can be filled again by adsorption of water. Octahedral configuration of iridium is not presented completely as well as nucleophilic attack of water and removal of proton is merged to one step to not overcrowd the scheme.

\section{The Stability-number}

Significantly higher dissolution rates of iridium, but also higher OER rates were observed for amorphous $\mathrm{IrO}_{\mathrm{x}}$ and perovskites in comparison to crystalline $\mathrm{IrO}_{2}$. In order to take into account the possible effect of much higher amount of oxygen formed on amorphous and perovskite structures on dissolution, we introduce a metric characterizing the activity vs. stability performance of a given catalyst. The so called Stability-number (S-number) is defined as the ratio between the amount of evolved oxygen (calculated from $\mathrm{Q}_{\text {total }}$ ) and the amount of dissolved iridium (extracted from ICP-MS data). The S-number describes how many oxygen molecules are formed per one iridium atom lost into the electrolyte. Consequently it is independent of the amount of involved active sites, surface area, or catalyst loading and gives an illustrative comparison of the stability of various materials. Moreover, unlike current efficiency, the S-number can be calculated without knowing the exact nature of the dissolved species and can be applied to neutral species. The higher the number, the more stable is the active centre of the electrocatalyst. Based on dissolution measurements presented in Fig. 3, the highest S-numbers were calculated for crystalline $\mathrm{IrO}_{2}$ (Fig. S9). Perovskite 
based iridium oxides possess the lowest S-numbers with two orders of magnitude less oxygen

381 evolved per dissolved iridium compared to rutile $\mathrm{IrO}_{2}$. However, the influence of initially dissolved iridium from defects as well as possible stabilization during longer operation should not be overlooked in these short measurements (see discussion Fig. S10).

In order to demonstrate a more relevant study on stability of the investigated powders

385

386 and to gain further understanding on possible correlations of OER-mechanism and dissolution mechanism, we varied the current per mass of iridium using galvanostatic steps of $\sim 5-20 \mathrm{~min}$ until a steady dissolution rate was observed (see Fig. S11). According to Fig. 7a the Snumbers match the ones presented in the supporting information using a short linear scan of potential. Over a wide range of current densities (0.01 to $\left.1 \mathrm{~A} \mathrm{mg}_{\mathrm{Ir}}{ }^{-1}\right)$ fairly constant $\mathrm{S}$ numbers were observed, indicating a direct relation between oxygen evolution and dissolution for all materials. The difference in the absolute value of the S-number can be assigned to: (i) a weaker bonding of the lattice oxygen in amorphous structures compared to crystalline ones, enabling a direct participation in the OER with the formation of metastable, activated iridium complexes that are more prone to dissolution, (ii) the amount of activated oxygen atoms surrounding one iridium centre, which is assumed to be higher in the case of leached $\mathrm{Ba}_{2} \mathrm{PrIrO}_{6}$ (see Fig. 1e) in comparison to amorphous iridium oxides and rutile $\mathrm{IrO}_{2}$, enabling the occurrence of instable iridium centres with two oxygen vacancies caused by recombination of two activated oxygen atoms. ${ }^{50}$ For crystalline $\mathrm{IrO}_{2}$ the number of activated oxygen atoms is restricted to the outer surface while bulk oxygen will not participate and maintain a high coordination of the iridium atom resulting in a significantly lower probability for the iridium atom to dissolve out of the structure.

The constancy of the S-number, observed over a wide range of current densities allows a relation of dissolution and lifetime of the catalyst using equation 1, presented in Fig. $7 \mathrm{~b}$.

$$
t=\frac{S \cdot z \cdot F \cdot m}{j \cdot M}
$$

$t=$ lifetime of the catalyst (s), $S=$ Stability-number, $z=$ electrons per transferred $\mathrm{O}_{2}$, $F=$ Faraday constant $\left(96485 \mathrm{C} \mathrm{mol}^{-1}\right), m=$ loaded mass of iridium $\left(\mathrm{g} \mathrm{cm}^{-2}\right), j=$ applied current density $\left(\mathrm{A} \mathrm{cm}^{-2}\right), M=$ molar mass of iridium $\left(192.2 \mathrm{~g} \mathrm{~mol}^{-1}\right)$.

$$
\text { Hereby, lifetimes of a few days }\left(\mathrm{Ba}_{2} \mathrm{PrIrO}_{6}\right) \text {, one month }\left(\mathrm{IrO}_{\mathrm{x}}\right) \text { and one year }\left(\mathrm{IrO}_{2}\right) \text { were }
$$
obtained when considering a constant current density of $0.2 \mathrm{~A} \mathrm{mg}_{\mathrm{Ir}}^{-1}$. Note these findings are 
410 specific for the electrochemical cell used. Lifetimes in a PEM system can deviate, which is 411 discussed in more detail in the supporting information (see Fig. S12 and related text).

412 In order to widen our scope, also sputtered films were investigated using the same 413 procedure (Fig. 7c). The trends resemble the ones observed for powders. Additionally, S414 numbers for sputtered metallic iridium are presented, which drop at current densities above 50 $415 \mathrm{~mA} \mathrm{~cm}{ }^{-2}$. A similar trend was observed for $\mathrm{IrO}_{\mathrm{x}}$ in Fig. 7a. The reason is the onset of a second 416 dissolution pathway forming $\mathrm{IrO}_{4}{ }^{2-}$, which is expected to occur at potentials $>1.8 \mathrm{~V} \mathrm{vs} \mathrm{RHE}^{9}$ 417 (see Fig. S13). Through kinetic stabilization, the latter pathway is successfully suppressed for 418 rutile $\mathrm{IrO}_{2}$ at even higher potentials (reported as well for the hydrogen region ${ }^{39}$ ). For metallic 419 iridium and amorphous iridium oxide, a self-accelerating degradation process can be observed 420 when a critical current density is reached by insufficient loading or degraded catalyst. The 421 degradation of $\mathrm{IrO}_{2}$, however, is exclusively linked to the amount of oxygen evolved and not 422 to the applied potential. 

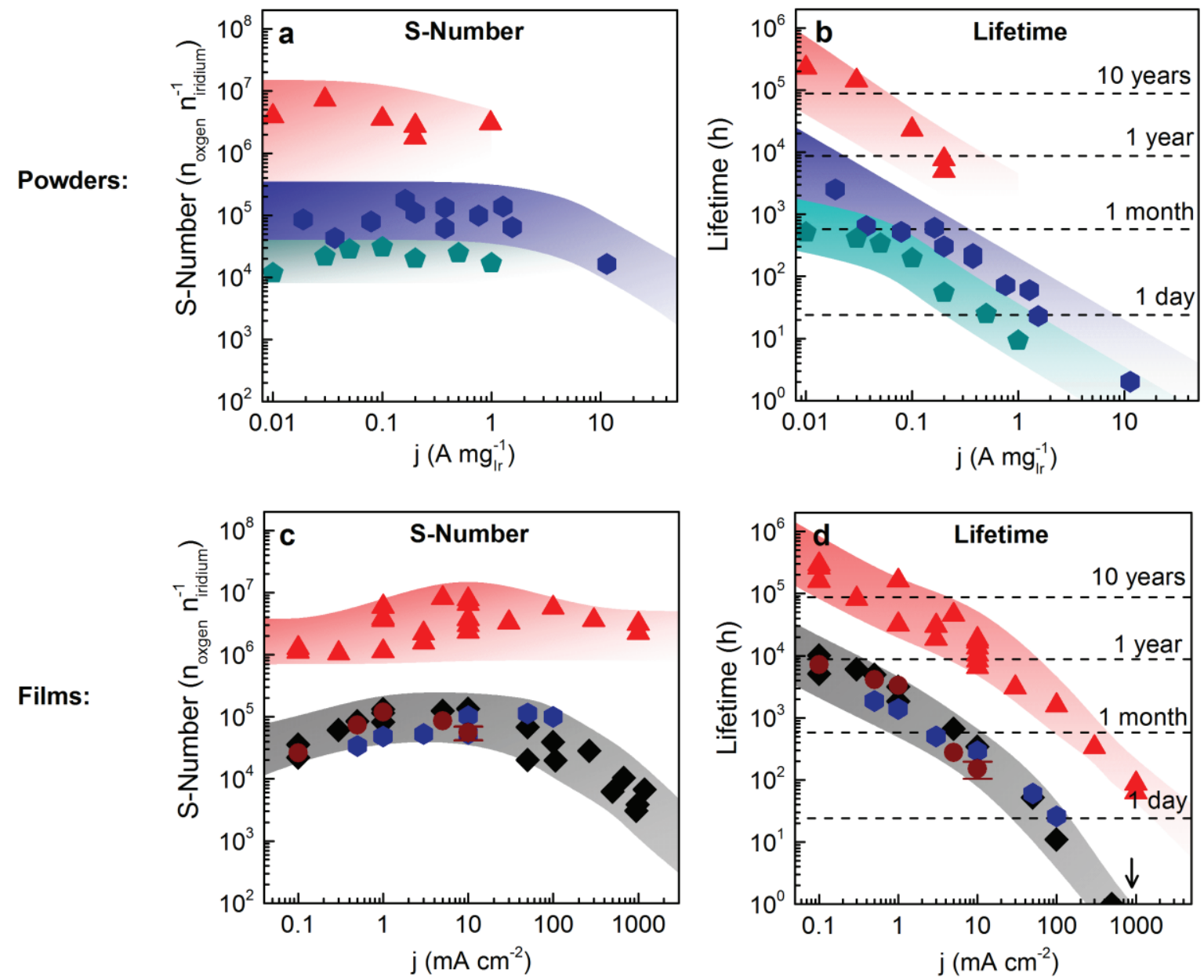

$\Delta$ Cryst. $\mathrm{IrO}_{2} \rightarrow$ Hydrous IrO $_{\mathrm{x}}-\mathrm{Ba}_{2} \mathrm{PrIrO}_{6} \odot \mathrm{SrIrO}_{3}$

Ir metal

Figure 7. Investigation of S-Number and lifetime depending on the current load. (a, c) Stability-number (S-

Number) plotted versus mass specific current density for powders (a) and geometric current density for sputtered films (c). $\mathrm{Ba}_{2} \mathrm{PrIrO}_{6}$ was leached for 5 days in advance. (b, d) Calculation of the catalyst's lifetime, based on equation 1 for powders (b) and films (d). This approach assumes "steady state" dissolution and neglects increased dissolution towards the end of life due to loss of surface area. In case of powder materials $m$ equals the mass of loaded iridium. In case of films $m$ was set to $50 \mu \mathrm{g}_{\mathrm{Ir}} \mathrm{cm}^{-2}$ which equals film thicknesses of about $100 \mathrm{~nm}$ $\mathrm{SrIrO}_{3}, 50 \mathrm{~nm} \mathrm{IrO}_{2}$, and $20 \mathrm{~nm}$ iridium metal. Measurements were carried out in $0.1 \mathrm{M} \mathrm{HClO}_{4}$. 
In this work, a new metric for stability benchmarking of electrocatalysts, the so called Snumber is introduced, enabling direct evaluation of lifetimes, illustrative comparison of stability properties, and insights into degradation mechanisms. This concept can be adapted to a wide range of electrochemical reactions and can be understood as an electrochemical turn over number (TON) known from the field of heterogeneous catalysis.

Moreover, for the first time the in situ dissolution of various iridium-based oxides including highly crystalline, perovskite-based, and amorphous structures over a wide range of current densities is presented. The measurements were carried out in acidic electrolyte with iridium-based perovskites undergoing severe leaching. Hence, in acidic conditions, explanations for the enhanced activity based on electronic interactions with rare earth or alkali elements are debatable. The resulting amorphous iridium oxide, which is part of several studies on innovative OER materials, ${ }^{1-5}$ shows exceptional high activity accompanied by high iridium dissolution. We demonstrate the participation of activated lattice oxygen atoms as trigger for the boost in activity and the high dissolution rate due to arising oxygen vacancies.

Based on our findings, future research in this field should be devoted to formation of ultrathin films of crystalline iridium oxide on stable and conductive substrates with high surface area, such as fluorine doped tin oxide (FTO), antimony doped tin oxide (ATO) or similar materials. ${ }^{63}$ By doing so the lower intrinsic activity and the fact that exclusively the surface of the material is participating in the reaction could be compensated. In case the superior activity of amorphous iridium oxides is utilized, stabilization of the weak iridium

461 intermediate caused by oxygen vacancies will be of great importance. Further fundamental 462 research in understanding dissolution processes of amorphous iridium oxides will be essential 463 to reach this goal. 


\section{Methods}

471 Powder materials. $\mathrm{A}_{2} \mathrm{BIrO}_{6}(\mathrm{~A}=\mathrm{Pr}, \mathrm{Nd}$ or $\mathrm{Y} ; \mathrm{B}=\mathrm{Ba}$ or $\mathrm{Sr})$ double perovskites were 472 synthesized in alumina crucibles using $\mathrm{BaCO}_{3}, \mathrm{SrCO}_{3}, \operatorname{Pr}_{6} \mathrm{O}_{11}, \mathrm{Nd}_{2} \mathrm{O}_{3}, \mathrm{Y}_{2} \mathrm{O}_{3}$ and metallic 473 iridium powder, respectively. The standard solid-state reactions are described in the 474 literature. ${ }^{35}$ All reactions were carried out in air and the products were furnace-cooled to room 475 temperature. The powders were intermittently reground during the synthesis. Amorphous 476 iridium oxide (iridium (IV) oxide dihydrate) and crystalline iridium oxide (iridium (IV) 477 oxide) were purchased from Alfa Aesar. To ensure complete crystallisation, iridium (IV) 478 oxide was additionally calcined at $600^{\circ} \mathrm{C}$ for $48 \mathrm{~h}$ in air.

479 For powder samples the electrodes were prepared by dropcasting $0.3 \mu \mathrm{L}$ suspension on a 480 glassy carbon plate. All suspensions contained the same amount of iridium $\left(0.27 \mathrm{mg} \mathrm{mL}^{-1}\right)$. 481 For some measurements of crystalline $\mathrm{IrO}_{2}$, however, the concentration was enhanced to 4.5 $482 \mathrm{mg} \mathrm{mL}{ }^{-1}$ in order to exceed the detection limit of the ICP-MS and measure reasonable 483 currents in the cyclic voltammograms. To avoid detachment $20 \mu \mathrm{L}$ of Nafion solution (5 w\%, 484 Sigma-Aldrich) was added to $5 \mathrm{~mL}$ of suspension. The dried spots $(\varnothing \sim 1 \mathrm{~mm})$ were rinsed 485 with water and located with the help of a vertical camera attached to the SFC. The measurements were carried out by placing the spot in the centre of the SFC's opening area

Film materials. Ir metal films were deposited by physical vapour deposition in a magnetron sputter system (AJA ATC 2200-V) with a confocal target setup. The $100 \mathrm{~nm}$ thick Ir film was deposited on a thermally oxidized $\left(1.5 \mu \mathrm{m} \mathrm{SiO}_{2}\right)$ 4-inch diameter $\mathrm{Si}$ (100) wafer with an intermediate, $10 \mathrm{~nm}$ thick, Ti adhesion layer. Sputter targets were pre-cleaned at $150 \mathrm{~W}$ direct current (DC), $4 \mathrm{~Pa}, 300 \mathrm{~s}$ for $\mathrm{Ti}$ and $100 \mathrm{~W} \mathrm{DC}, 4 \mathrm{~Pa}, 30 \mathrm{~s}$ for Ir. The deposition was performed at $150 \mathrm{~W}$ DC, $1.3 \mathrm{~Pa}, 150 \mathrm{~s}$ for Ti and $60 \mathrm{~W} \mathrm{DC}, 0.66 \mathrm{~Pa}, 1200 \mathrm{~s}$ for Ir. Both layers were deposited with substrate rotation. The sputter system was operated with a base pressure $<2.6 \times 10^{-5} \mathrm{~Pa}$ and an Ar plasma.

For high current density measurements on iridium metal, lift-off photolithography was used to structure the thin film and create small catalyst dots (see Fig. S14). By doing so the bubble detachment in the SFC was facilitated significantly. For the lift-off a bilayer photoresist system consisting of an LOR $20 \mathrm{~B}$ (MicroChem) bottom and an AZ 1518 (MicroChemicals) top layer was utilized. After deposition the photoresist was removed in a cleaning cascade of acetone and isopropanol under ultrasonic agitation. 
Hydrous $\mathrm{IrO}_{\mathrm{x}}$ films were grown on the sputtered iridium spots by 300 square wave pulses of $5040.5 \mathrm{~s}$ between $0.05 \mathrm{~V}$ and $1.4 \mathrm{~V}$ vs. RHE.

505 Crystalline $\mathrm{IrO}_{2}$ films were produced on $\mathrm{Si} / \mathrm{SiO}_{2}$ wafers via reactive sputtering in the presence 506 of $\mathrm{O}_{2}$ using a DC magnetron sputtering machine (BesTech $\mathrm{GmbH}$, Berlin) followed by 507 additional thermal treatment at $600^{\circ} \mathrm{C}$ for $48 \mathrm{~h}$ in air.

$508 \mathrm{SrIrO}_{3}$ film samples were epitaxially grown using on-axis, RF magnetron sputtering of a $509 \mathrm{Sr}_{4} \mathrm{IrO}_{6}$ target on (001) $\mathrm{SrTiO}_{3}$. Due to two-dimensional growth, the surface of the samples 510 was atomically flat, with $0.4 \mathrm{~nm}$ steps corresponding to the pseudo-cubic cell parameter. X511 ray diffraction showed that the films were single crystals, oriented [110] perpendicular to the 512 substrate $^{64}$.

513 Labelled samples. Thin films of isotope labelled reactively sputtered $\operatorname{Ir}^{18} \mathrm{O}_{2}$ were deposited 514 by magnetron sputtering (BesTech $\mathrm{GmbH}$, Berlin) at $100 \mathrm{~W}$ in a mixture of ${ }^{18} \mathrm{O}_{2}(99.00$ at.\%, 515 Sigma Aldrich) and Ar as the sputter gas and the chamber pressure was regulated to $0.5 \mathrm{~Pa}$ at 516 room temperature. The base vacuum before deposition was $2.0 \times 10^{-6} \mathrm{~Pa}$. The $\varnothing 3$ inch target of 517 Ir (99.9\%, Evochem) was pre-cleaned by sputtering against closed shutters prior to 518 deposition. To prepare films with a minimal surface roughness, on the smooth substrates of 519 single crystalline $\mathrm{Si}(100)$ wafers with a $1.5 \mu \mathrm{m}$ thermal $\mathrm{SiO}_{2}$ diffusion and reaction barrier 520 layer were used. The resulting thickness of the obtained coating was approximately $80 \mathrm{~nm}$. 521 After the deposition films were annealed in vacuum at $500^{\circ} \mathrm{C}$ during 2 hours. Unlabelled 522 reactively sputtered $\mathrm{Ir}^{16} \mathrm{O}_{2}$ were deposited using a mixture of ${ }^{16} \mathrm{O}_{2}$ and Ar. All other 523 conditions were kept as described before.

524 The ${ }^{18} \mathrm{O}$-labelled samples of hydrous $\operatorname{Ir}^{18} \mathrm{O}_{\mathrm{x}}$ were prepared using a solution of $0.1 \mathrm{M} \mathrm{HClO}_{4}$ in $525 \mathrm{H}_{2}{ }^{18} \mathrm{O}(97.76$ at.\%, Campro Scientific $\mathrm{GmbH})$ applying a square wave potential program with 526 upper and lower potential limits of 1.4 and $0.04 \mathrm{~V}$ vs. RHE, respectively (600 cycles at 0.5 $527 \mathrm{~Hz}$ ) to a sputtered Ir film (see description above). Afterwards the electrodes were carefully 528 rinsed with ultrapure $\mathrm{H}_{2}{ }^{16} \mathrm{O}$ water and threated in the vacuum at $80^{\circ} \mathrm{C}$ during 2 hours. 529 Unlabelled samples were prepared using electrolyte containing $0.1 \mathrm{M} \mathrm{HClO}_{4}$ (Suprapur ${ }^{\circledR} 70 \%$ $530 \mathrm{HClO}_{4}$, Merck) in ultrapure $\mathrm{H}_{2}{ }^{16} \mathrm{O}$ water (PureLab Plus system, Elga, $18 \mathrm{M} \Omega \mathrm{cm}$, TOC $<3$ $531 \mathrm{ppb})$, using the same electrochemical program.

532 All ${ }^{18}$ O-labelled samples were prepared right before the OLEMS measurements and 533 transferred in a desiccator to avoid exchange of lattice oxygen in topmost layers with air. 
Electrochemical measurements. Dissolution measurements were performed in argon purged $0.1 \mathrm{M} \mathrm{HClO}_{4}$ using a scanning flow cell (SFC) connected to an inductively coupled plasma mass spectrometer (ICP-MS) ${ }^{65}$. A graphite rod and an $\mathrm{Ag} / \mathrm{AgCl}$ electrode (Metrohm, Germany) were used as counter and reference electrode, respectively. The electrolyte was prepared by dilution of concentrated acid (Suprapur ${ }^{\circledR} 70 \% \mathrm{HClO}_{4}$, Merck) in ultrapure water (PureLab Plus system, Elga, $18 \mathrm{M} \Omega \mathrm{cm}$, TOC $<3 \mathrm{ppb}$ ). Flow rate through the cell was 352 $\mu \mathrm{L} \mathrm{min}{ }^{-1}$. Steady performance of the ICP-MS (NexION 300X, Perkin Elmer) was ensured by addition of internal standard solution $\left({ }^{187} \mathrm{Re},{ }^{130} \mathrm{In}\right)$ downstream to the flow cell and daily calibration. A scheme of the SFC is presented in the supporting information (Fig. S14).

OLEMS (online electrochemical mass spectrometer) measurements were carried out using a SFC - set up, previously described elsewhere. ${ }^{66}$ In contrast to the SFC connected to ICP-MS, here the surface area of the working electrode was $0.125 \mathrm{~cm}^{2}$ and a PTFE tip from the top of the cell through an extra vertical channel was introduced. A $50 \mu \mathrm{m}$ thick PTFE Gore-Tex membrane with a pore size of $20 \mathrm{~nm}$, through which products can evaporate into the vacuum system of the mass spectrometer (Max 300 LG, Extrel) was mounted onto the very end of the tip. The approximate distance from the tip to the electrode was about $50 \mu \mathrm{m}$, which is determined by the thickness of the silicon ring sealing around the cell opening and the applied contact force. These parameters were kept constant during the whole set of measurements.

A potentiostat (Reference 600, Gamry) was used for the electrochemical measurements with both setups.

Materials characterisation. Scanning electron microscopy (SEM) measurements were performed in secondary electron mode using a Leo $1550 \mathrm{VP}$ (Zeiss) operated at $15 \mathrm{kV}$ and 6 mm sample distance. For energy-dispersive X-ray spectroscopy (EDS) the acceleration voltage was increased to $30 \mathrm{kV}$.

Measurements of x-ray photoelectron spectra were performed applying a monochromatic Al $\mathrm{K} \alpha \mathrm{X}$-ray source (1486.6 eV) operating at $15 \mathrm{kV}$ and $25 \mathrm{~W}$ (Quantera II, Physical Electronics, Chanhassen, MN, USA). The binding energy scale was referenced to the $\mathrm{C} 1 \mathrm{~s}$ signal at 285.0 eV.

TEM and SAED analysis were performed with a CM20 FEG electron microscope (from Philips) operated at $200 \mathrm{kV}$. The samples were prepared by dropcasting about $5 \mu \mathrm{l}$ of catalyst suspension onto a gold TEM grid coated with a Lacey carbon film (NH7, Plano GmbH). 


\section{Data availability}

569 The authors declare that the main data supporting the findings of this study are available

570

571

572

573

574

575

576

577

578

579

580

581

582

583

584

585

586

587

588

589

590

591

592

593

594

595

596

597

598

599

600

601

602

603

\section{Acknowledgements}

The authors acknowledge funding by the German Federal Ministry of Education and Research (BMBF) within the Kopernikus Project P2X and a further project (Kz: 033RC1101A). S. G. acknowledges financial support from BASF. O.K. acknowledges financial support from the Alexander von Humboldt Foundation. K. M. acknowledges financial support from the DFG under the project number MA4819/4-1. L. F. and Z. L. acknowledge support from the Agence Nationale de la Recherche grant SOCRATE ANR-15-CE30-0009-01. Additional thanks go to Katharina Hengge and Thomas Gänsler for carrying out the TEM and SAED measurements.

\section{References}

1 Seitz, L. C. et al. A highly active and stable $\mathrm{IrOx} / \mathrm{SrIrO} 3$ catalyst for the oxygen evolution reaction. Science 353, 1011-1014, doi:10.1126/science.aaf5050 (2016).

2 Diaz-Morales, O. et al. Iridium-based double perovskites for efficient water oxidation in acid media. Nature communications 7, 12363, doi:10.1038/ncomms12363 (2016).

3 Nong, H. N. et al. Oxide-supported $\operatorname{IrNiO}(x)$ core-shell particles as efficient, costeffective, and stable catalysts for electrochemical water splitting. Angewandte Chemie 54, 2975-2979, doi:10.1002/anie.201411072 (2015).

4 Reier, T. et al. Molecular Insight in Structure and Activity of Highly Efficient, Low-Ir Ir-Ni Oxide Catalysts for Electrochemical Water Splitting (OER). J Am Chem Soc 137, 13031-13040, doi:10.1021/jacs.5b07788 (2015).

5 Lettenmeier, P. et al. Nanosized IrO(x)-Ir Catalyst with Relevant Activity for Anodes of Proton Exchange Membrane Electrolysis Produced by a Cost-Effective Procedure. Angewandte Chemie 55, 742-746, doi:10.1002/anie.201507626 (2016).

6 Sun, W., Song, Y., Gong, X.-Q., Cao, L.-m. \& Yang, J. An efficiently tuned d-orbital occupation of IrO2by doping with $\mathrm{Cu}$ for enhancing the oxygen evolution reaction activity. Chem. Sci. 6, 4993-4999, doi:10.1039/c5sc01251a (2015).

7 Sun, W. et al. OER activity manipulated by IrO6 coordination geometry: an insight from pyrochlore iridates. Scientific reports 6, 38429, doi:10.1038/srep38429 (2016).

8 Sun, W., Song, Y., Gong, X. Q., Cao, L. M. \& Yang, J. Hollandite Structure K(x approximately 0.25)IrO2 Catalyst with Highly Efficient Oxygen Evolution Reaction. ACS Appl Mater Interfaces 8, 820-826, doi:10.1021/acsami.5b10159 (2016). 
6049 Pourbaix, M. Atlas of electrochemical equilibria in aqueous solutions. (National $605 \quad$ Association of Corrosion Engineers, 1974).

$60610 \quad$ Geiger, S. et al. Activity and Stability of Electrochemically and Thermally Treated (2016).

11 Cherevko, S. et al. Stability of nanostructured iridium oxide electrocatalysts during oxygen evolution reaction in acidic environment. Electrochemistry Communications 48, 81-85, doi:10.1016/j.elecom.2014.08.027 (2014).

12 Abbott, D. F. et al. Iridium Oxide for the Oxygen Evolution Reaction: Correlation between Particle Size, Morphology, and the Surface Hydroxo Layer from Operando XAS. Chemistry of Materials 28, 6591-6604, doi:10.1021/acs.chemmater.6b02625 (2016).

13 Beni, G., Schiavone, L. M., Shay, J. L., Dautremont-Smith, W. C. \& Schneider, B. S. Electrocatalytic oxygen evolution on reactively sputtered electrochromic iridium oxide films. Nature (London) 282, 281-283, doi:10.1038/282281a0 (1979).

14 Bockris, J. O. M. \& Otagawa, T. The Electrocatalysis of Oxygen Evolution on Perovskites. J. Electrochem. Soc. 131, 290-302 (1984).

15 Bockris, J. O. M., Otagawa, T. \& Young, V. Solid state surface studies of the electrocatalysis of oxygen evolution on perovskites. J. Electroanal. Chem. 150, 633643 (1983).

16 Kortenaar, M. V., Vente, J. F., Ijdo, D. J. W., Müller, S. \& Kötz, R. Oxygen evolution and reduction on iridium oxide compounds Journal of Power Sources 56, 51-60 (1995).

17 Bursell, M., Pirjamali, M. \& Kiros, Y. La0.6Ca0.4CoO3, La0.1Ca0.9MnO3 and LaNiO3 as bifunctional oxygen electrodes. Electrochim. Acta 47, 1651-1660 (2002).

18 Suntivich, J., May, K. J., Gasteiger, H. A., Goodenough, J. B. \& Shao-Horn, Y. A perovskite oxide optimized for oxygen evolution catalysis from molecular orbital principles. Science 334, 1383-1385, doi:10.1126/science.1212858 (2011).

19 Grimaud, A. et al. Double perovskites as a family of highly active catalysts for oxygen evolution in alkaline solution. Nature communications 4, 2439, doi:10.1038/ncomms3439 (2013).

20 Rincon, R. A. et al. Evaluation of perovskites as electrocatalysts for the oxygen evolution reaction. Chemphyschem : a European journal of chemical physics and physical chemistry 15, 2810-2816, doi:10.1002/cphc.201402137 (2014).

21 Petrie, J. R., Jeen, H., Barron, S. C., Meyer, T. L. \& Lee, H. N. Enhancing Perovskite Electrocatalysis through Strain Tuning of the Oxygen Deficiency. J Am Chem Soc 138, 7252-7255, doi:10.1021/jacs.6b03520 (2016).

22 Zhu, L., Ran, R., Tadé, M., Wang, W. \& Shao, Z. Perovskite materials in energy storage and conversion. Asia-Pacific Journal of Chemical Engineering 11, 338-369, doi:10.1002/apj.2000 (2016).

23 Zhu, Y. et al. Enhancing Electrocatalytic Activity of Perovskite Oxides by Tuning Cation Deficiency for Oxygen Reduction and Evolution Reactions. Chemistry of Materials 28, 1691-1697, doi:10.1021/acs.chemmater.5b04457 (2016).

$24 \mathrm{Wu}, \mathrm{Z}$. et al. Effect of Sr doping on the electrochemical properties of bi-functional

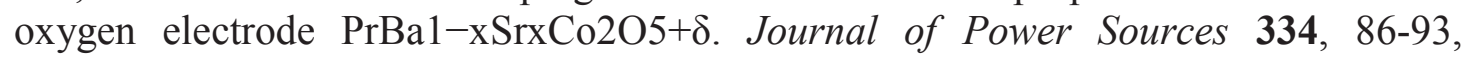
doi:10.1016/j.jpowsour.2016.10.013 (2016).

25 Chen, D., Wang, J., Zhang, Z., Shao, Z. \& Ciucci, F. Boosting oxygen reduction/evolution reaction activities with layered perovskite catalysts. Chemical communications 52, 10739-10742, doi:10.1039/c6cc04895a (2016). 
26 May, K. J. et al. Influence of Oxygen Evolution during Water Oxidation on the Surface of Perovskite Oxide Catalysts. The Journal of Physical Chemistry Letters 3, 3264-3270, doi:10.1021/jz301414z (2012).

27 Risch, M. et al. Structural Changes of Cobalt-Based Perovskites upon Water Oxidation Investigated by EXAFS. The Journal of Physical Chemistry C 117, 86288635, doi:10.1021/jp3126768 (2013).

28 Binninger, T. et al. Thermodynamic explanation of the universal correlation between oxygen evolution activity and corrosion of oxide catalysts. Scientific reports $\mathbf{5}, 12167$, doi:10.1038/srep12167 (2015).

29 Grimaud, A. et al. Activation of surface oxygen sites on an iridium-based model catalyst for the oxygen evolution reaction. Nature Energy 2, 16189, doi:10.1038/nenergy.2016.189 (2016).

30 Sen, F. G. et al. Towards accurate prediction of catalytic activity in IrO2nanoclusters via first principles-based variable charge force field. J. Mater. Chem. A 3, 1897018982, doi:10.1039/c5ta04678e (2015).

31 Gottesfeld, S. \& Srinivasan, S. Electrochemical and optical studies of thick oxide layers on iridium and their electrocatalytic activities for the oxygen evolution reaction. J. Electroanal. Chem. Interfacial Electrochem. 86, 89-104, doi:10.1016/S00220728(78)80358-1 (1978).

32 Reier, T., Weidinger, I., Hildebrandt, P., Kraehnert, R. \& Strasser, P. Electrocatalytic oxygen evolution reaction on iridium oxide model film catalysts: influence of oxide type and catalyst substrate interactions. ECS Trans. 58, 39-51, 14 pp., doi:10.1149/05802.0039ecst (2013).

33 Pfeifer, V. et al. The electronic structure of iridium and its oxides. Surface and Interface Analysis 48, 261-273, doi:10.1002/sia.5895 (2016).

34 Sanchez Casalongue, H. G. et al. In situ observation of surface species on iridium oxide nanoparticles during the oxygen evolution reaction. Angewandte Chemie 53, 7169-7172, doi:10.1002/anie.201402311 (2014).

$35 \mathrm{Fu}, \mathrm{W}$. T. \& Ijdo, D. J. W. On the space group of the double perovskite Ba2PrIrO6. Journal of Solid State Chemistry 178, 1312-1316, doi:10.1016/j.jssc.2005.02.003 (2005).

36 Strasser, P. Free Electrons to Molecular Bonds and Back: Closing the Energetic Oxygen Reduction (ORR)-Oxygen Evolution (OER) Cycle Using Core-Shell Nanoelectrocatalysts. Acc Chem Res 49, 2658-2668, doi:10.1021/acs.accounts.6b00346 (2016).

37 Minguzzi, A. et al. Observing the oxidation state turnover in heterogeneous iridiumbased water oxidation catalysts. Chemical Science 5, 3591, doi:10.1039/c4sc00975d (2014).

38 Pavlovic, Z., Ranjan, C., Gao, Q., van Gastel, M. \& Schloegl, R. Probing the structure of water oxidizing anodic Iridium oxide catalyst using Raman spectroscopy. $A C S$ Catalysis, doi:10.1021/acscatal.6b02343 (2016).

39 Cherevko, S. et al. Oxygen and hydrogen evolution reactions on $\mathrm{Ru}, \mathrm{RuO} 2$, Ir, and IrO2 thin film electrodes in acidic and alkaline electrolytes: A comparative study on activity and stability. Catalysis Today 262, 170-180, doi:10.1016/j.cattod.2015.08.014 (2016).

40 Trasatti, S. \& Petrii, O. A. Real surface area measurements in electrochemistry. $J$. Electroanal. Chem. 327, 353-376 (1992).

41 Angelinetta, C., Trasatti, S., Atanososka, L. D. \& Atanasoski, R. T. Surface properties of $\mathrm{RuO} 2+\mathrm{IrO} 2$ mixed oxide electrodes. Journal of Electroanalytical Chemistry and 

0728(86)80122-X (1986).

704

705

706

707

708

709

710

711

712

713

714

715

716

717

718

719

720

721

722

723

724

725

726

727

728

729

730

731

732

733

734

735

736

737

738

739

740

741

742

743

744

745

746

747

748

749

750

42 Burke, L. D. \& Murphy, O. J. Surface area-Voltammetric charge correlation for $\mathrm{RuO} 2 / \mathrm{TiO} 2-b a s e d$ anodes. Journal of Electroanalytical Chemistry and Interfacial Electrochemistry 112, 39-50, doi:http://dx.doi.org/10.1016/S0022-0728(80)80005-2 (1980).

43 Burke, L. D. \& Murphy, O. J. Cyclic voltammetry as a technique for determining the surface area of $\mathrm{RuO} 2$ electrodes. Journal of Electroanalytical Chemistry and Interfacial Electrochemistry 96, 19-27, doi:http://dx.doi.org/10.1016/S00220728(79)80299-5 (1979).

44 Minguzzi, A. et al. Easy Accommodation of Different Oxidation States in Iridium Oxide Nanoparticles with Different Hydration Degree as Water Oxidation Electrocatalysts. ACS Catalysis 5, 5104-5115, doi:10.1021/acscatal.5b01281 (2015).

45 Pickup, P. G. \& Birss, V. I. A model for anodic hydrous oxide growth at iridium. J. Electroanal. Chem. Interfacial Electrochem. 220, 83-100, doi:10.1016/00220728(87)88006-3 (1987).

46 Burke, L. D. \& Whelan, D. P. A voltammetric investigation of the charge storage reactions of hydrous iridium oxide layers. Journal of Electroanalytical Chemistry and Interfacial Electrochemistry 162, 121-141, doi:https://doi.org/10.1016/S00220728(84)80159-X (1984).

47 Fabbri, E., Habereder, A., Waltar, K., Kötz, R. \& Schmidt, T. J. Developments and perspectives of oxide-based catalysts for the oxygen evolution reaction. Catal. Sci. Technol. 4, 3800-3821, doi:10.1039/c4cy00669k (2014).

48 Reier, T., Nong, H. N., Teschner, D., Schlögl, R. \& Strasser, P. Electrocatalytic Oxygen Evolution Reaction in Acidic Environments - Reaction Mechanisms and Catalysts. Advanced Energy Materials, 1601275, doi:10.1002/aenm.201601275 (2016).

49 Rong, X., Parolin, J. \& Kolpak, A. M. A Fundamental Relationship between Reaction Mechanism and Stability in Metal Oxide Catalysts for Oxygen Evolution. ACS Catalysis 6, 1153-1158, doi:10.1021/acscatal.5b02432 (2016).

50 Grimaud, A. et al. Activating lattice oxygen redox reactions in metal oxides to catalyse oxygen evolution. Nature chemistry, doi:10.1038/nchem.2695 (2017).

51 Pfeifer, V. et al. Reactive oxygen species in iridium-based OER catalysts. Chem. Sci., doi:10.1039/c6sc01860b (2016).

52 Pfeifer, V. et al. In situ observation of reactive oxygen species forming on oxygenevolving iridium surfaces. Chem Sci 8, 2143-2149, doi:10.1039/c6sc04622c (2017).

53 Pfeifer, V. et al. The electronic structure of iridium oxide electrodes active in water splitting. Physical chemistry chemical physics : PCCP 18, 2292-2296, doi:10.1039/c5cp06997a (2016).

54 Willinger, E., Massue, C., Schlogl, R. \& Willinger, M. G. Identifying Key Structural Features of IrOx Water Splitting Catalysts. J Am Chem Soc 139, 12093-12101, doi:10.1021/jacs.7b07079 (2017).

55 Fierro, S., Nagel, T., Baltruschat, H. \& Comninellis, C. Investigation of the oxygen evolution reaction on $\mathrm{Ti} / \mathrm{IrO} 2$ electrodes using isotope labelling and on-line mass spectrometry. Electrochemistry Communications 9, 1969-1974, doi:10.1016/j.elecom.2007.05.008 (2007).

56 Rossmeisl, J., Qu, Z. W., Zhu, H., Kroes, G. J. \& Nørskov, J. K. Electrolysis of water on oxide surfaces. Journal of Electroanalytical Chemistry 607, 83-89, doi:10.1016/j.jelechem.2006.11.008 (2007). 
57 Ooka, H., Takashima, T., Yamaguchi, A., Hayashi, T. \& Nakamura, R. Element strategy of oxygen evolution electrocatalysis based on in situ spectroelectrochemistry. Chemical communications 53, 7149-7161, doi:10.1039/c7cc02204b (2017).

58 Bockris, J. O. M. Kinetics of Activation Controlled Consecutive Electrochemical Reactions: Anodic Evolution of Oxygen. The Journal of Chemical Physics 24, 817, doi:10.1063/1.1742616 (1956).

59 Mefford, J. T. et al. Water electrolysis on $\mathrm{La}(1-\mathrm{x}) \operatorname{Sr}(\mathrm{x}) \mathrm{CoO}(3-d e l t a)$ perovskite electrocatalysts. Nature communications 7, 11053, doi:10.1038/ncomms11053 (2016).

60 Cherevko, S., Geiger, S., Kasian, O., Mingers, A. \& Mayrhofer, K. J. J. Oxygen evolution activity and stability of iridium in acidic media. Part 2. - Electrochemically grown hydrous iridium oxide. Journal of Electroanalytical Chemistry 774, 102-110, doi:10.1016/j.jelechem.2016.05.015 (2016).

61 Kötz, R., Neff, H. \& Stucki, S. Anodic Iridium Oxide Films; XPS-Studies of Oxidation State Changes and O2-Evolution. J. Electrochem. Soc. 131, $72-77$ (1984).

62 Kasian, O., Grote, J. P., Geiger, S., Cherevko, S. \& Mayrhofer, K. J. J. The Common Intermediates of Oxygen Evolution and Dissolution Reactions during Water Electrolysis on Iridium. Angewandte Chemie 57, 2488-2491, doi:10.1002/anie.201709652 (2018).

63 Oh, H.-S., Nong, H. N. \& Strasser, P. Preparation of Mesoporous Sb-, F-, and InDoped SnO2Bulk Powder with High Surface Area for Use as Catalyst Supports in Electrolytic Cells. Advanced Functional Materials 25, 1074-1081, doi:10.1002/adfm.201401919 (2015).

64 Li, Z. Z., Schneegans, O. \& Fruchter, L. Synthesis of Perovskite SrIrO3 Thin Films by Sputtering Technique. arXiv:1610.03722 (2016).

65 Klemm, S. O., Topalov, A. A., Laska, C. A. \& Mayrhofer, K. J. J. Coupling of a high throughput microelectrochemical cell with online multielemental trace analysis by ICP-MS. Electrochemistry Communications 13, 1533-1535, doi:10.1016/j.elecom.2011.10.017 (2011).

66 Grote, J. P., Zeradjanin, A. R., Cherevko, S. \& Mayrhofer, K. J. Coupling of a scanning flow cell with online electrochemical mass spectrometry for screening of reaction selectivity. The Review of scientific instruments 85, 104101, doi:10.1063/1.4896755 (2014). 